\title{
Modelling erosion and sediment delivery from unsealed roads in southeast Australia
}

\author{
B. Fu, L.T.H. Newham*, J.B. Field \\ The Fenner School of Environment and Society, The Australian National University, Building 48A, Canberra, ACT 0200, Australia
}

Received 30 June 2008; received in revised form 22 September 2008; accepted 5 October 2008

\begin{abstract}
Unsealed roads and tracks are potentially significant sources of diffuse pollutants, particularly sediment. This paper describes the application and development of a road erosion and sediment transport model in the Moruya-Deua and Tuross River catchments of southeast Australia. An empirical model based on the Washington Road Surface Erosion Model (WARSEM) is applied using typically widely available spatial data sets and field-collected data. The results suggest that approximately $21 \mathrm{kt}$ and $35 \mathrm{kt}$ of sediment respectively are produced annually from road erosion in the Moruya-Deua and Tuross River catchments, but that less than $10 \%$ of the sediment is delivered to streams. Surprisingly, about half of the delivered sediment is derived from only $4 \%$ of the total road network. Testing of the model shows that the model outputs are likely to overestimate road erosion rates. To address this problem, catchment-specific testing of the factors of the model and improving knowledge of the processes of road to stream sediment transport are required.
\end{abstract}

(C) 2008 IMACS. Published by Elsevier B.V. All rights reserved.

Keywords: Road erosion modelling; Suspended sediment; Sediment delivery; Road management; WARSEM

\section{Introduction}

The significance of unsealed roads to off-site water quality decline is well recognised, especially in forested catchments $[1,2,8,12,18,19]$. For example, erosion rates from unsealed roads have been shown to be four and six orders of magnitude higher than undisturbed hillslope areas in the US Virgin Islands [19] and coastal southeast Australia [2], respectively. It is therefore critical to understand road erosion and sediment delivery processes, and to quantify potential road-derived sediment contributions for the effective management of water quality at catchment scales.

Techniques for quantifying erosion from roads include the use of road-side and stream monitoring, sediment tracing and modelling. Each has its inherent advantages and limitations. For example, sediment traps are inefficient for estimating the contribution of fine sediment [19]. It is difficult to distinguish road-derived sediment from other sources using stream monitoring techniques. Environmental tracing results are affected by stream water geochemistry, organic matter and particle size sorting [9], and the interpretation of tracing results can hence be difficult [10]. Environmental models have the advantages of catchment-scale application and prediction beyond current conditions, but model calibration and testing are difficult without access to appropriate data for comparison.

\footnotetext{
* Corresponding author. Tel.: +61 261258129; fax: +61 261258395.

E-mail address: lachlan.newham@anu.edu.au (L.T.H. Newham).
} 
Road erosion models are relatively less developed than hillslope erosion models which have been a focus of active research and development over the last half century. A review of road erosion models has been completed by Fu and Newham [11]. The findings of the review are summarised below:

- many road models adapt theories of hillslope erosion processes, and the inherent limitations of the 'parent' models are retained;

- the data required as inputs to road models are seldom routinely collected;

- many road models show a significant bias towards simulating erosion process, with much less consideration given to delivery process;

- for management application, simpler models are potentially more directly useful; and

- model testing and uncertainty analysis is seldom reported, but is fundamental to advance capability in road erosion modelling.

This paper describes the application and modification of a road erosion and sediment delivery model to assess road erosion in the Moruya-Deua and Tuross River catchments of southeast Australia.

\section{The road model}

\subsection{Model selection}

The scope of this study requires the road model to estimate contributions of road sediment at a catchment scale, be relatively simple, have modest data requirements, and be testable. The Washington Road Surface Erosion Model (WARSEM) was selected as a basis for the road model for the following reasons:

- it can be applied at catchment scales;

- it incorporates many of the major factors thought to control rates of road erosion;

- it can be used for management purposes;

- it can be implemented as a GIS-based model;

- it has flexibility to be modified and applied in different environmental settings;

- most data required for the model are available or can be routinely collected in the field; and

- the characteristics of the physical environment where WARSEM was developed (e.g. rainfall, dominant lithology, landuse, and topography) is similar to the Moruya-Deua and Tuross River catchments.

\subsection{WARSEM}

WARSEM is an empirical model used to estimate long-term average sediment delivery from roads to streams. It was developed by the Washington State Department of Natural Resources [6]. WARSEM was developed as a Microsoft Access database application, but has been integrated into a GIS model (SEDMODL) [6]. WARSEM is spatially distributed by road segment. It can be applied at large catchment scales and the effects of a variety of best management practices can be simulated to aid catchment decision-making.

WARSEM considers sediment sources from multiple features, including the road surface, the table drain, and cutslope. A base erosion rate is estimated as a function of average annual rainfall. This rate is multiplied by a series of factors that act to increase or decrease the base erosion rate. The delivery of road-derived sediment to a stream is modelled using a sediment delivery ratio based on the study of Megahan and Ketcheson [16]. The factors are derived from literature on the effects of changes in road characteristics on road erosion and sediment delivery [6]. A maximum of 15 data inputs are required but these vary according to the intended purpose of the modelling [6]. These inputs include annual average rainfall, road surface materials, vegetation cover, slope, traffic and maintenance, and the contributing area for the road surface, cutslope and table drain. The factor-based approach used in WARSEM has many similarities to the Universal Soil Loss Equation (USLE) [21]. The factors of WARSEM are directly related to road surface erosion while those of the USLE are estimated for agriculture lands. 

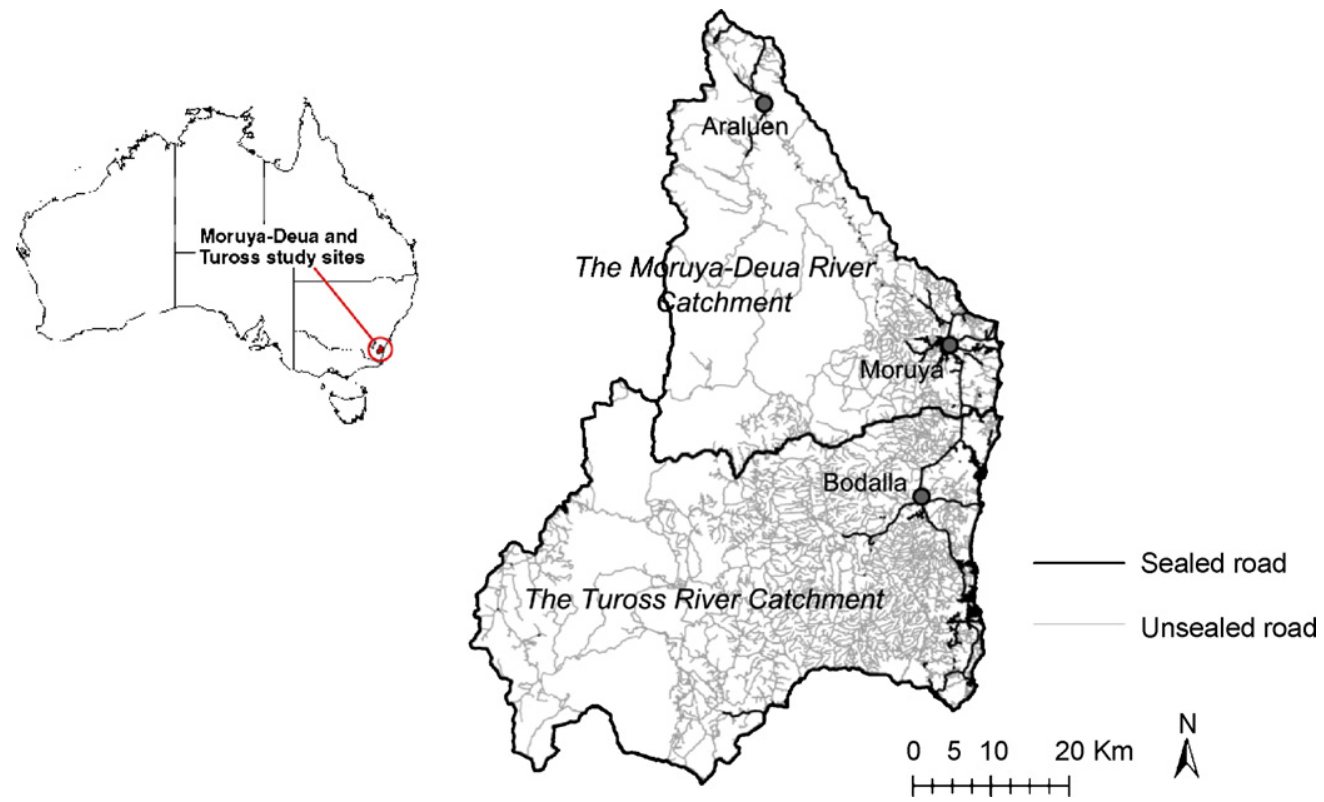

Fig. 1. The location of study catchments (left) and the distribution of road network in the study catchments (right). The spatial data describing the local road network were obtained from the Department of Environment and Climate Change, NSW.

\section{Description of case study catchments}

The Moruya-Deua and Tuross River catchments are located along the southeast coast of Australia (Fig. 1). The annual average rainfall ranges from approximately $700 \mathrm{~mm}$ to $1100 \mathrm{~mm}$ declining from east to west. The Moruya-Deua River drains a catchment of approximately $1500 \mathrm{~km}^{2}$. The Tuross River Catchment is located to the south and adjacent to the Moruya-Deua catchment. It has a total area of approximately $2100 \mathrm{~km}^{2}$. Both catchments are dominated by native eucalypt forests with metasedimentary lithologies.

The Moruya-Deua and Tuross River catchments have road lengths of $1120 \mathrm{~km}$ and $2090 \mathrm{~km}$, respectively, with road densities of $0.75 \mathrm{~km} / \mathrm{km}^{2}$ for the Moruya-Deua River Catchment, and $1.00 \mathrm{~km} / \mathrm{km}^{2}$ for the Tuross River Catchment. Most of the roads are located in the lower parts of the catchments and have highest densities in forest areas (Fig. 1). Roads in these areas were constructed for access for forestry harvesting and associated activities and for fire suppression.

Approximately $89 \%$ and $97 \%$ of the roads are unsealed in the Moruya-Deua and Tuross River catchments, respectively. Most of the unsealed roads have slopes between $10^{\circ}$ and $30^{\circ}$. The road surface is typically worn gravel. A total of 72 and 124 unsealed road crossing of perennial and intermittent streams in the Moruya-Deua and Tuross River catchments have been estimated from the available GIS data. It is likely that a larger number of road stream crossings are present when minor drainage links are considered. The proportions of the roads that are within $100 \mathrm{~m}$ to the stream network in the Moruya-Deua and Tuross River catchments are $23 \%$ and 20\%, respectively.

\section{Road modelling for the study catchments}

\subsection{Model structure}

Cutslopes are not considered in this study because their stability was assessed as moderately high across the study catchments through field-based inspection. The road model modified from WARSEM [6] and used in this research is described below:

$$
\begin{aligned}
& E_{d}=E A_{c} S D R_{R-S} \\
& E=E_{b} G_{f} F_{f} S_{f} T_{f} L W \\
& E_{b}=3 \times 10^{-5} R^{1.5}
\end{aligned}
$$


Table 1

Factor values for the road model.

\begin{tabular}{lll}
\hline Factor & Class & Factor value \\
\hline Geology $\left(G_{f}\right)$ & Metasediment & 5 \\
& Granite & 5 \\
& Others & 1 \\
Surface $\left(F_{f}\right)$ & Sealed & 0 \\
& Unsealed arterial road & 0.5 \\
& Unsealed subarterial road & 0.5 \\
& Unsealed local road & 0.7 \\
Road slope $\left(S_{f}\right)$ & Unsealed track vehicular & 1 \\
& Unsealed path & \\
Traffic $\left(T_{f}\right)$ & $<5 \%$ & 0.2 \\
& $5-10 \%$ & 1 \\
& $>10 \%$ & 1 \\
& Arterial roads & 10 \\
Contributing area proportion $\left(A_{c}\right)$ & Subarterial roads & 2 \\
\hline
\end{tabular}

$$
S D R_{R-S}=\max \left(0, \frac{103.6 \mathrm{e}^{-D / 32.9}-4.95}{100}\right)
$$

Here $E_{d}$ is the total sediment delivered to a stream from each road segment $(\mathrm{kg} / \mathrm{yr}) ; E$ is the road surface sediment yield from each road segment $(\mathrm{kg} / \mathrm{yr}) ; A_{c}$ is the contributing area proportion (percentage); $S D R_{R-S}$ is the sediment delivery ratio from road to stream (dimensionless); $E_{b}$ is an erosion rate based on average annual rainfall $(\mathrm{kg} / \mathrm{m} / \mathrm{yr}$ ); $G_{f}$ is a geologic erosion factor (dimensionless); $F_{f}$ is a road surfacing factor (dimensionless); $S_{f}$ is a road slope factor (dimensionless); $T_{f}$ is a traffic factor (dimensionless); $L$ is the segment length $(\mathrm{m}) ; W$ is road width $(\mathrm{m}) ; R$ is average annual rainfall $(\mathrm{mm} / \mathrm{yr})$; and $D$ is the distance between road drain outlet and streams $(\mathrm{m})$ (assuming that the maximum sediment travel distance is $100 \mathrm{~m}$ ).

The factor values are based on those of WARSEM [6], with modifications corresponding to available data on the catchment geology, surface, and traffic. The values used are listed in Table 1.

Field investigation of the study area suggests that the distinctions of different road configurations (i.e. insloped, outsloped and crown) are not simple. Most often, a road segment has a combination of different configurations. Thus, instead of using road configuration to estimate road surface contributing area (as in WARSEM), a fixed contributing area proportion $\left(A_{c}\right)$ factor is used. The $A_{c}$ is the percentage of road surface that has effective runoff delivered to the drain outlet. The remaining road surface delivers diffuse runoff to the lower hillslope from the road side. Considering the low energy in diffuse roadside runoff and high levels of ground cover in the catchment, this proportion of the road surface is assumed not to deliver sediment to streams.

\subsection{Model application}

The application of WARSEM in the Moruya-Deua and Tuross River catchments is divided into three steps: (i) spatial data processing, (ii) modelling, and (iii) summarising and mapping. The spatial data processing involves using an Arc Macro Language (AML) script to generate spatial inputs for the model. This is followed by modelling sediment yields and delivery for each segment using Microsoft Access. ArcGIS is used to summarise and map the results. The processes are illustrated in Fig. 2 and the details on how the spatial data were obtained are described below.

The spatial data used for the application of the model are a $25 \mathrm{~m}$ digital elevation model (DEM), geology coverage, and a road network coverage. All data were obtained from NSW government agencies. The road network data contains the classification of the roads based on their function (primary, arterial, subarterial, local, track and path), and road 


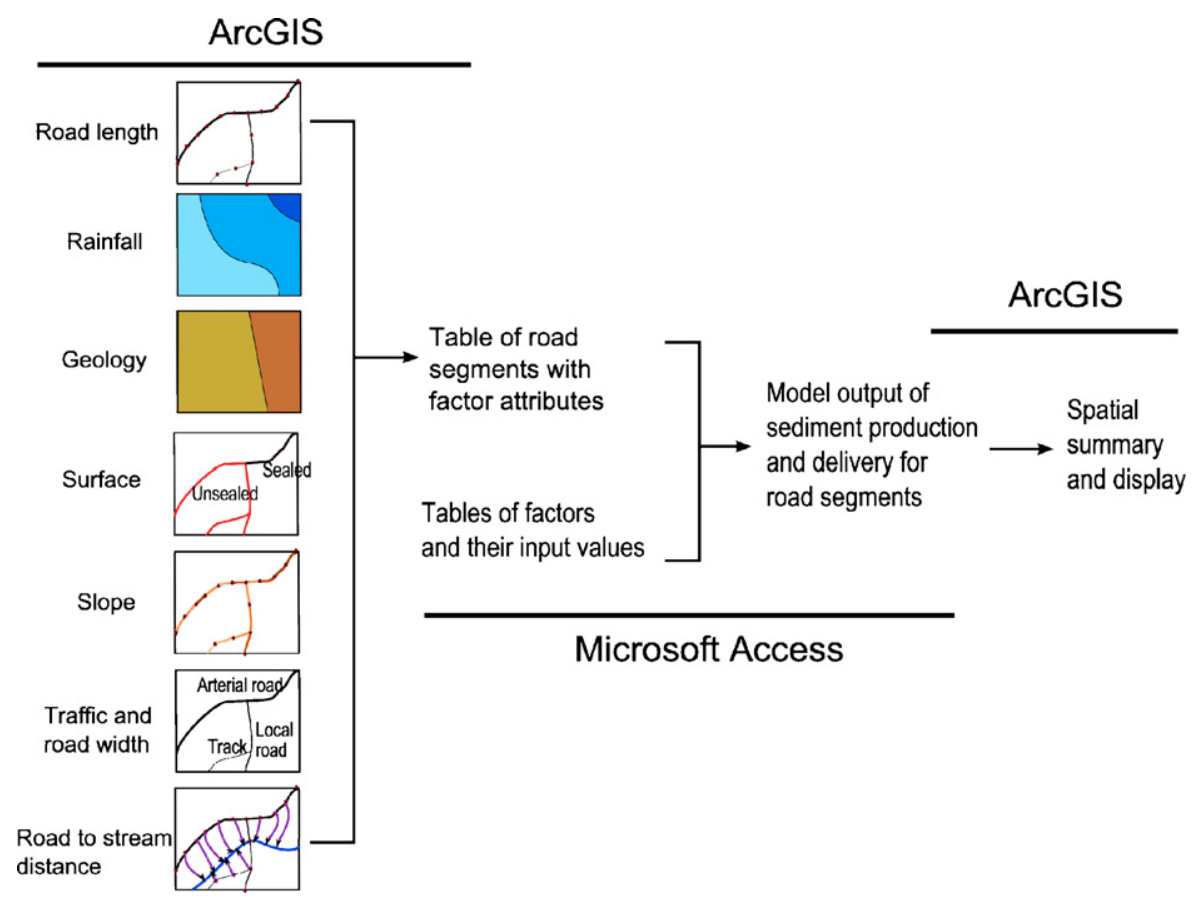

Fig. 2. The processes of road modelling for the study catchments.

surface (sealed or unsealed). These data are representative of what is available for remainder of southeast Australia and hence this study provides a strong basis for further application of the model outside the study catchments.

For using WARSEM, it is necessary to know the segment length, width and slope for all road segments in the road network. However, these data are not available in the study area, and surveying all roads is impracticable. Thus, the average segment length and width extrapolated from field measurements were used to divide roads into segments, assuming the segment length and width are constant for roads of the same function (arterial, subarterial, etc.). The road slope was calculated by determining the difference in elevation of both the ends of a road segment from digital elevation data, and the length of the segment. The road surface is assumed to be planar between the ends of a road segment.

Field measurements such as segment length, width, and the contributing area proportion were collected for selected road segments. A road segment was identified as the length of a road that flows to a drain. The ends of a road segment are a hilltop, or mitre, culvert, stream crossing, or the end of a road. Road drain outlets were located using a hand held GPS. A distance-measuring wheel was used to measure the length of the road segment and a measuring tape was used to measure the width of a road segments (defined as the road surface area that bears traffic). The contributing area of the road surface proportion was recorded based on observation. Four types of roads were sampled: arterial roads, subarterial roads, local roads, and tracks. The number of segments, and the length and width of roads are summarised in Table 2.

An annual average rainfall surface was produced by ordinary kriging, using data from 49 rain gauges within and surrounding the catchments obtained from the Australian Bureau of Meteorology databases. The mean value of average annual rainfall at the two ends of a road segment was used for model input for each segment. The road-to-stream distance

Table 2

Summary of the number of sampled segments and the average length and width.

\begin{tabular}{|c|c|c|c|c|}
\hline Road type & Arterial & Subarterial & Local & Track \\
\hline Number of segments & 25 & 12 & 20 & 20 \\
\hline Average segment length (m) & 50 & 100 & 70 & 55 \\
\hline Average road width (m) & 5.4 & 3.9 & 3.2 & 2.8 \\
\hline
\end{tabular}


was calculated using the flow distance of the road end with lower elevation. A flow distance grid was obtained through analysis of the DEM data. The geology of the road was obtained directly from an overlay of the road network with the available spatial data.

\subsection{Results}

The overall modelled estimates of sediment yields from unsealed roads of the Moruya-Deua and Tuross River catchments are approximately $21 \mathrm{kt} / \mathrm{yr}$ and $35 \mathrm{kt} / \mathrm{yr}$, respectively. About $9 \%$ and $6 \%$ of the sediment is delivered to the streams in the Moruya-Deua and Tuross River catchments. Model simulations show that the roads that deliver sediment to stream network account for approximately $16 \%$ and $14 \%$ of the total road lengths in the Moruya-Deua and Tuross River catchments, respectively. The distribution of erosion rates and sediment delivery are shown in Fig. 3.

Three roads are identified as having consistently high sediment delivery: the Araluen Road in the Moruya-Deua River Catchment; and the Eurobodalla-Reedy Creek Road and the Bourkes-Wadbilliga Road in the Tuross River Catchment. All of these roads are either arterial or subarterial roads, which have higher traffic levels, are typically wider than other types of unsealed roads, and are typically adjacent to major streams. The Araluen Road, which constitutes $2.6 \%$ of the total road length in the catchment, is estimated to deliver approximately $820 \mathrm{t} / \mathrm{yr}$ of sediment to streams, equivalent to about $64 \%$ of the total road-derived sediment in the Moruya-Deua River Catchment. The road segments of the Eurobodalla-Reedy Creek Road and the Bourkes-Wadbilliga Road that deliver sediment to streams are only $1.4 \%$ of the total length of road in the Tuross River Catchment but deliver $35 \%$ of the total sediment in that catchment.
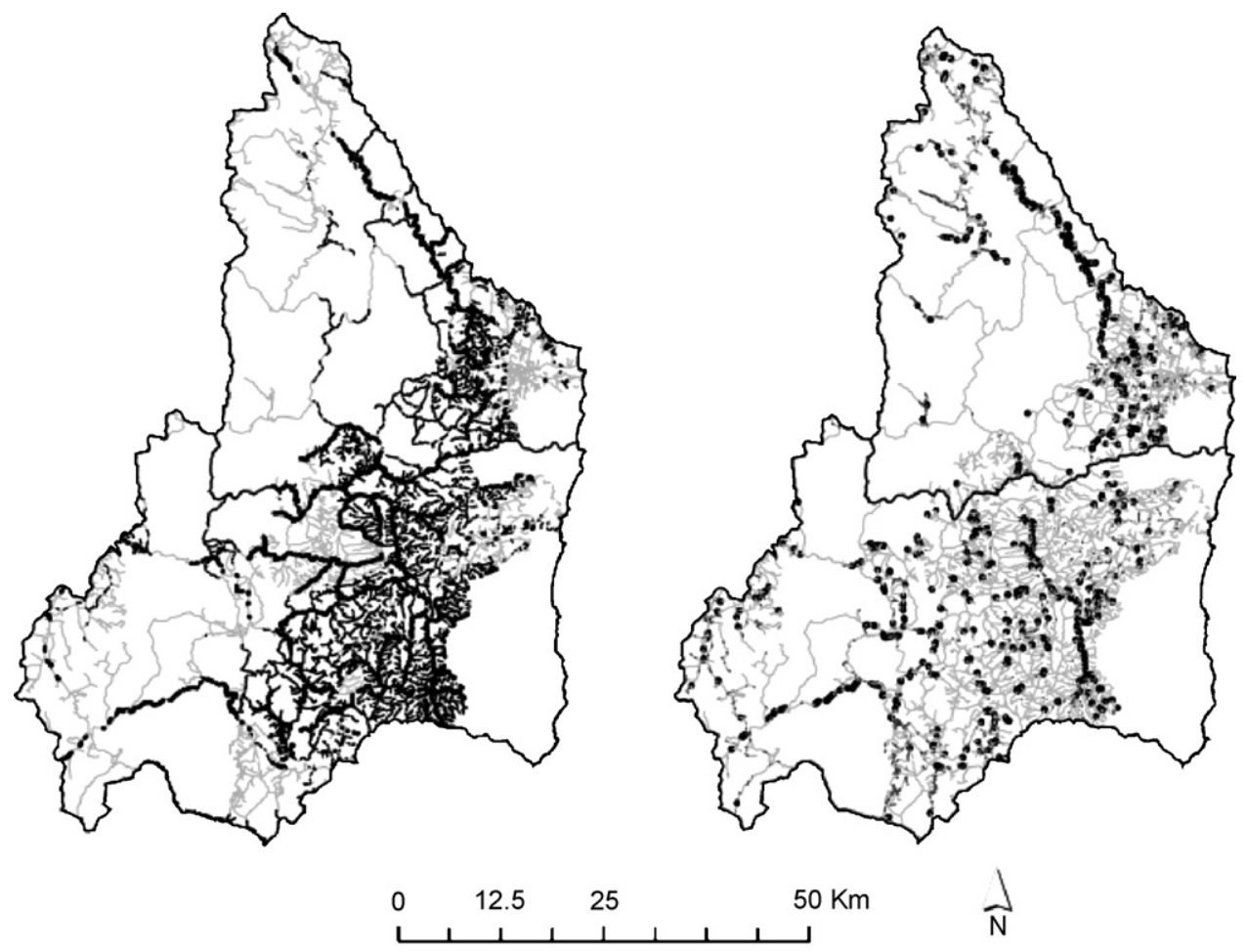

Road erosion (t/yr)

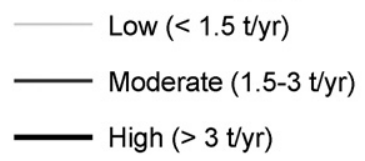

Sediment delivery (t/yr)

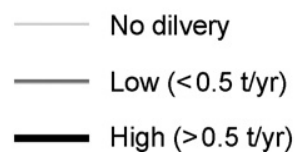

Fig. 3. Road surface erosion rate (left) and sediment delivery (right) in the Moruya-Deua and Tuross River catchments. 


\section{Management options}

The factors used in the model that can be changed for management practices include the road surface type, traffic volume, road contributing area proportion and segment length (controlled by drain spacing). Re-gravelling or sealing native dirt roads leads to a lower surface factor in the model. Reducing the traffic volume results in lesser disturbance of the road surface, hence lesser estimated erosion. Changing the road configuration, increasing the proportion of outsloped surface of a road segment (within safety standards) can reduce the road contributing area proportion, hence reduce sediment delivery (but not erosion). Shortening the road segment length by addition of drains can reduce the volume of road runoff and hence the possibility of delivering sediment to the streams [13]. Currently, consideration of the road length is not included in the sediment delivery model, and hence its impacts on sediment delivery cannot be identified but are discussed later.

Three scenarios were run for selected road segments: (i) re-gravelling the road surface, which reduces $F_{f}$ by 0.4 ; (ii) reducing traffic level, which reduced $T_{f}$ by 3 ; and (iii) reducing road contributing area proportion, which reduced $A_{c}$ by 0.3 . These scenarios were applied on the roads that were identified as having high sediment yields, with a total management length of $60 \mathrm{~km}$, equivalent to $1.8 \%$ of the total road length. The results show that re-gravelling on these roads can reduce the sediment delivery by $35-50 \%$ in both catchments. Nearly a third of sediment delivery can be reduced if the traffic levels are reduced. Simulations showed that among the tested scenarios, reducing the effective road contributing area by changing the road surface configuration is the least effective means of reducing sediment delivery.

\section{Discussion and recommendations}

\subsection{Model testing}

Model testing and uncertainty analysis are critical for developing an understanding of model outputs [14]. However, they are seldom reported for road erosion and delivery models [11]. The factors limiting model testing and uncertainty analysis include access to data of sufficient quantity, and of appropriate spatial and temporal resolution and reliability for comparison against the model outputs, and the large inherent variability in the data. There is unfortunately no data available for direct testing of the performance model applied in this study. However, two indirect tests were undertaken. The first compared the modelled outputs of sediment delivery from road model with the monitoring data of sediment yields from the river gauges of the Moruya-Deua and Tuross River catchments just upstream of the tidal reach $[4,5]$. The second means of testing the model involved a comparison of the model outputs for a road network in southeast Australia [20].

The annual average sediment delivery from roads is compared with event-based suspended sediment loads in 2005 [4,5] (Table 3). The suspended sediment loads were estimated using a log discharge-concentration regression [15], with consideration of the time shift between the concentration and flow to account for hysteresis between concentration and flow. The road-derived sediment accounts for $30 \%$ and $80 \%$ of the total sediment loads in the Moruya-Deua and Tuross River catchments, respectively. Direct testing of the road model could not be made from the event-based suspended sediment loads due to the difficulty in estimating accurately the inputs of other sediment sources, sediment deposition, and the differences in the time frame of modelling and monitoring. However, such comparison may suggest that the outputs on road sediment delivery are within the reasonable magnitudes for the study catchments.

A one-year monitoring program of road erosion was conducted during 2002-2003 in the Central Highlands area of the Great Dividing Range, Victoria [20]. These data are used to compare against the predicted outputs of WARSEM based on the published road conditions. The comparison between the modelled and measured erosion rates is illustrated in Fig. 4. Overall, the road model slightly overestimates generation from most road segments. Significant overestimation

Table 3

Comparing sediment delivery from roads, and total SS yields in 2005 [4,5].

\begin{tabular}{llll}
\hline Catchment & Road sediment (t/yr) & Total sediment $(\mathrm{t} / \mathrm{yr})$ & Road sediment proportion $(\%)$ \\
\hline Moruya-Deua & 1300 & 3800 & 34 \\
Tuross & 1400 & 1700 & 82 \\
\hline
\end{tabular}




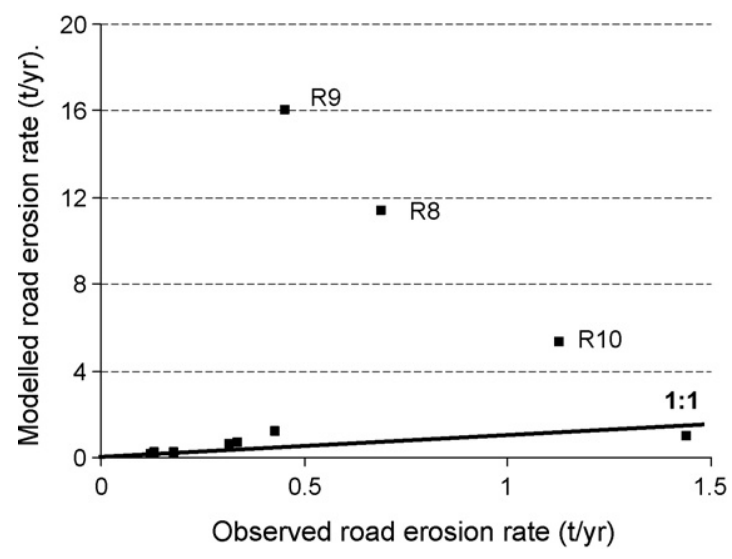

Fig. 4. Comparison of annual road erosion rates between observed [20] and modelled values. Estimated erosion rates for segments R8-10 are significantly higher than observed values, possibly due to the overestimation of traffic and surface factors.

of sediment generation is made for segments R8, R9 and R10 relative to the observed data. The significant overestimation of road erosion rates for these segments is likely due to the overestimation of sensitive factors such as traffic and surface factors.

\subsection{Model improvement through collection of monitoring data}

The fundamental uncertainty in this study is the application of an empirical road erosion model outside the area in which the model was originally developed. An investigation on the response of erosion of the road surface on the various factors is required to adapt the model to Australian conditions and to build confidence in the model outputs. The method recommended for such investigation includes field monitoring of road surface erosion rates under a range of likely factor conditions. For example, the response of road surface erosion resulting from changes in road slope can be quantified using rainfall simulators to measure sediment runoff at different slopes while holding other factors such as annual rainfall, geology, surface and traffic constant. These investigations are beyond the scope of this study, but they are important components for future research to improve the reliability of road erosion modelling using WARSEM and more generally to develop capability in road erosion models.

The model application is largely based on widely available data in southeast Australia, and some limited field measurements. However, monitoring data such as the location of the drains (i.e. the segment length), road width, road slope, more detailed traffic levels and road surface conditions are lacking. As a result, uncertainty in model application on individual segments can be high. In this study, model inputs on segment length and width were based on a small subset of roads sampled and, as resources allow, steps should be taken to address this data gap.

Road monitoring programs are expensive. However, the results of this paper suggest that most of the sediment delivered to the streams is derived from a very small proportion of the road network. Hence improving road monitoring programs on the identified critical road erosion sections will improve confidence in model predictions. This iterative approach combining data collection and modelling can be applied to other catchments, to refine monitoring programs based on the results of preliminary modelling from generally available data, and then to refine the model application by improving the quality of the monitoring data.

\subsection{Sediment delivery ratio}

In WARSEM, the $S D R_{R-S}$ is a function of the distance between the road drain outlet and streams. However, it is argued that the contributing road area is also an important factor affecting the volume of sediment delivered to streams $[3,13]$. This is because larger contributing areas produce larger volumes of runoff, which have greater potential to reach streams.

Hairsine et al. [13] estimate the probability of road runoff reaching the streams based on both the distance between the road drainage outlet and streams, and the road contributing area. But, there has been no investigation to relate 
hydrological connectivity to $S D R_{R-S}$. It is believed that conceptually the hydrological connectivity model [13] has the broad behaviour expected for sediment. When the road drainage outlet is very close to the streams, the $S D R_{R-S}$ is high regardless of the road contributing area. However, when the road-stream distance increases, the road contributing area becomes important. A large road contributing area keeps the $S D R_{R-S}$ high, even the road to stream distance is large. Data are needed to test this conceptual framework for sediment and generate a sediment delivery model. If this relationship is identified, the impact of changing drainage spacing on sediment delivery can then be modelled, and greater confidence placed on the model outputs.

\subsection{Management implications}

Identifying the likely locations of highest sediment generation from a road network is itself effective at identifying opportunities to control erosion. Field inspection of such sites may quickly reveal whether the generated sediment is being delivered to areas of concern in problematic quantities, and whether the best solution is improved road management and drainage or improved off-road practices such as detention ponds. On the other hand, simply identifying the sediment delivery potential of road segment is also useful to identify potential road segments for further investigation or monitoring on sediment generation, and to assess alternative road or drainage locations to control sediment from roads [7].

Models containing stochastic variables can be used to define the probability of erosion. WARSEM does not use a probabilistic approach for prediction, but this approach has been used in other erosion models. For example, Megahan et al. [17] used Monte Carlo simulation to predict the probability of occurrence of sediment yields from granitic fillslopes in Idaho, USA, under various levels of ground cover density. Such probabilistic modelling can be introduced in WARSEM to help land managers define the risks from road erosion, as well as assess management alternatives.

\section{Conclusions}

Unsealed roads are recognised as an important source of diffuse sediment requiring robust models for their assessment. In this study the WARSEM road erosion model was applied to identify critical road segments for sediment delivery. WARSEM was modified according to data availability in the study catchments. These data are also generally available in southeast Australia, making it possible to apply a similar model in other areas.

It was found that approximately half of the road sediment delivery is derived from only $4 \%$ of the roads in the Moruya-Deua and Tuross River catchments. Improved management of these critical road segments can cost effectively reduce sediment inputs. Sediment delivery was assessed under three management scenarios. Re-gravelling was found to be the most effective management option in reducing sediment delivery.

Two approaches have been used to indirectly test the model outputs: (i) using monitoring data of sediment load from the catchment outlet; and (ii) comparing erosion rates reported for Victorian forest roads. Both testing approaches suggest that the road model may overestimate erosion rates and sediment delivery, likely due to the overestimation of sensitive factors such as traffic and surface.

Due to the limitation of the road measurement data, the uncertainty of the model may be high. However, the model provides a useful starting point for more detailed analysis and objective and transparent method of identifying priority sites for management intervention. Investigation on the response of erosion rates on various sensitive factors such as traffic, slope, surfacing, and $S D R_{R-S}$ should be the focus of future research. A conceptual framework is suggested to estimate $S D R_{R-S}$ as a function of both the distance between the road drain outlet and the steam, and the road contributing area. With such research greater confidence can be placed in the outputs of the modelling and effective management of sediment inputs can be achieved.

\section{Acknowledgements}

This research was undertaken with funding from the Australian Research Council and Eurobodalla Shire Councils as part of project LP0560439. Support from the Australian National University and the Department of Environment and Climate Change were also provided and are gratefully acknowledged. 


\section{References}

[1] D.M. Anderson, L.H. Macdonald, Modelling road surface sediment production using a vector geographic information system, Earth Surface Processes and Landforms 23 (1998) 95-107.

[2] J. Croke, P. Hairsine, P. Fogarty, Sediment transport, redistribution and storage on logged forest hillslopes in south-eastern Australia, Hydrological Processes 13 (1999) 2705-2720.

[3] J. Croke, S. Mockler, Gully initiation and road-to-stream linkage in a forested catchment, southeastern Australia, Earth Surface Processes and Landforms 26 (2001) 205-217.

[4] J.J. Drewry, R.S.B. Greene, L.T. Newham, B.F.W. Croke, The role of soil regolith properties, river suspended sediment and nutrient concentrations during storm events in the Moruya and Tuross catchments, NSW, in: I.C. Roach (Ed.), Regolith 2005 - Ten Years of CRC LEME, CRC LEME, Adelaide and Canberra, 2005, pp. 78-82.

[5] J.J. Drewry, L.T.H. Newham, B.F.W. Croke, Suspended sediment, nitrogen and phosphorus concentrations and exports during storm-events to the Tuross estuary, Australia, Journal of Environmental Management (2008).

[6] K. Dubé, W. Megahan, M. Mccalmon, Washington Road Surface Erosion Model (WARSEM) Manual, State of Washington, Department of Natural Resources, 2004.

[7] C.S. Eastaugh, P.K. Rustomji, P.B. Hairsine, Quantifying the altered hydrologic connectivity of forest roads resulting from decommissioning and relocation, Hydrological Processes 22 (2008) 2438-2448.

[8] A.R. Forsyth, K.A. Bubb, M.E. Cox, Runoff, sediment loss and water quality from forest roads in a southeast Queensland coastal plain Pinus plantation, Forest Ecology and Management 221 (2006) 194-206.

[9] I.D.L. Foster, J.A. Lees, Tracers in geomorphology: theory and applications in tracing fine particulate sediments, in: I.D.L. Foster (Ed.), Tracers in Geomorphology, John Wiley \& Sons Ltd, Chichester, 2000, pp. 3-20.

[10] B. Fu, J.B. Field, L.T. Newham, Tracing the source of sediment in Australian coastal catchments, in: R.W. Fitzpatrick, P. Shand (Eds.), Regolith 2006 - Consolidation and Dispersion of Ideas, CRC LEME, Perth, 2006, pp. 100-104.

[11] B. Fu, L.T. Newham, A review of road erosion and sediment delivery models, Environmental Modelling \& Software, in review.

[12] R.B. Grayson, S.R. Haydon, M.D.A. Jayasuriya, B.L. Finlayson, Water quality in mountain ash forests - separating the impacts of roads from those of logging operations, Journal of Hydrology 150 (1993) 459-480.

[13] P.B. Hairsine, J.C. Croke, H. Mathews, P. Fogarty, S.P. Mockler, Modelling plumes of overland flow from logging tracks, Hydrological Processes 16 (2002) 2311-2327.

[14] A.J. Jakeman, R.A. Letcher, J.P. Norton, Ten iterative steps in development and evaluation of environmental models, Environmental Modelling \& Software 21 (2006) 602-614.

[15] R.A. Letcher, A.J. Jakeman, M. Calfas, S. Linforth, B. Baginska, I. Lawrence, A comparison of catchment water quality models and direct estimation techniques, Environmental Modelling \& Software 17 (2002) 77-85.

[16] W.F. Megahan, G.L. Ketcheson, Predicting downslope travel of granitic sediments from forest roads in Idaho, Journal of the American Water Resources Association 32 (1996) 371-382.

[17] W.F. Megahan, S.B. Monsen, M.D. Wilson, Probability of sediment yields from surface erosion on granitic roadfills in Idaho, Journal of Environmental Quality 20 (1991) 53-60.

[18] J.A. Motha, P.J. Wallbrink, P.B. Hairsine, R.B. Grayson, Unsealed roads as suspended sediment sources in an agricultural catchment in south-eastern Australia, Journal of Hydrology 286 (2004) 1-18.

[19] C.E. Ramos-Scharrón, L.H. Macdonald, Runoff and suspended sediment yields from an unpaved road segment, St John, US Virgin Islands, Hydrological Processes 21 (2007) 35-50.

[20] G.J. Sheridan, P.J. Noske, A quantitative study of sediment delivery and stream pollution from different forest road types, Hydrological Processes 21 (2007) 387-398.

[21] W.C. Wischmeier, D.D. Smith, Predicting rainfall erosion losses - a guide to conservation planning, in: Agricultural Handbook, vol. 537, U.S. Department of Agriculture, Washington, DC, 1978. 